\title{
THE INVESTIGATION OF THE CIVIL AVIATION SECTOR UNDER THE CRITERIA OF AIRLINE SELECTION
}

\author{
DOI: 10.17261/Pressacademia.2019.1080 \\ PAP-V.9-2019(27)-p.126-131
}

\section{Tuzun Tolga Inan ${ }^{1}$,}

${ }^{1}$ Istanbul Gelişim University, Faculty of Economics and Social Sciences, Istanbul, Turkey.

ttolgainan83@gmail.com, ORCID: 0000-0002-5937-9217

To cite this document

Inan, T., T., (2019). The investigation of the civil aviation sector under the criteria of airline selection. PressAcademia Procedia (PAP), V.9, p.126-131

Permemant link to this document: http://doi.org/10.17261/Pressacademia.2019.1080

Copyright: Published by PressAcademia and limited licenced re-use rights only.

\begin{abstract}
Purpose- The main aim of this study is to determine a big competition which is experienced between Airlines in the Civil Aviation Sector these days. After September 112001 Crisis, there was a major decline in the Civil Aviation Sector. People gave up travel by aircrafts and in these times a new strategy occured which its name is Low Cost Transportation Strategy, with this strategy the civil aviation sector reached its old power. By this growth agents came to the point of extinction with the strategy of Aer Lingus. Aer Lingus's system is concentrated with the ticket sales via the Internet. The number of agents and the prices of the tickets have increased by this way the civil aviation sector has continued its growth. In this article in the growing Civil Aviation Sector, an assessment is presented with the concepts of; customer satisfaction, on time performance, factors affect the choice of airlines, applications in airline ticket prices and how the system operates which determine ticket prices over the Internet with the concept of the system in Europe.

Methodology- In order to achieve this aim, the criteria affecting the selection of airlines under six chapters have been evaluated under the heading of System in the European Market.

Conclusion- As a result of the analysis, seven different issues affecting the choice of airline in the civil aviation sector were examined. As a result of these examinations, ticket price, timely departure on the second hand and comfort-service concepts especially on short-haul flights have become important topics in passenger selection.
\end{abstract}

Keywords: Full service transportation, charter transportation, low cost transportation, on-time performance, passenger satisfaction. JEL Codes: Y50, 7Y80, Y90, Z00.

\section{HAVAYOLU SEÇIMINI ETKILEYEN KRITERLER ALTINDA SIVIL HAVACILIK SEKTÖRÜNÜN INCELENMESi}

\section{ÖZET}

Amaç- Bu çalışmanın temel amacı, günümüzde Sivil Havacılık Sektöründe Havayolları arasında büyük rekabet yaşanmaktadır. 11 Eylül 2001 Krizinden sonra ekonomik olarak büyük düşüş yaşayan ve insanların uçağa binme tercihlerinden vazgeçtiği sektörde Düşük Maliyetli Taşımacılık anlayışı ile Sivil Havacılık Sektörü eski gücüne ulaşmıştır. Bu büyüme Düşük Maliyetli Havayollarından Aer Lingus'un başlattığı sistem ile acenteler yok olma noktasına gelmiştir. Aer Lingus'un sistemi ile İnternet üzerinden bilet satışları yoğunlaşmış ve acentelerin da büyük oranda azalması ile bilet fiyatlarında yaşanan düşüş ile sektör büyümesini sürdürmektedir. Bu çalışmada, büyüyen Sivil Havacılık Sektöründe; yolcu memnuniyeti, zamanında kalkış performansı, havayolu seçimini belirleyen unsurlar, havayolu bilet fiyatlarındaki uygulamalar ve internet üzerinden bilet satışı sisteminin nasıl çalıştığı ile Avrupa pazarındaki sistem anlayışı konuları anlatılacak ve yolcular açısından bir değerlendirme sunulacaktır.

Yöntem- Bu amaca ulaşmak için, altı bölüm altında havayolu seçimini etyileyen kriterler Avrupa Pazarındaki Sistem Anlayışı Başlığı altında değerlendirilmiştir.

Sonuç- Yapılan analizler sonucunda, sivil havacılık sektöründe havayolu seçimini etkileyen yedi farklı konu incelenmiştir. Bu incelemeler neticesinde öncelikli olarak bilet fiyatı, ikincil olarak zamanında kalkış, üçüncü olarak da özellikle kısa mesafe uçuşlarda konfor-hizmet kavramları yolcuların havayolu seçiminde önem arz eden başlıklar olmuşlardır.

Anahtar Kelimeler: Geleneksel taşımacılık, charter taşımacılık, düşük maliyetli taşımacılık, zamanında kalkış, yolcu memnuniyeti. JEL Kodları: Y50, 7Y80, Y90, Z00. 


\section{Giriş}

Sivil Havacııık Sektöründe artan rekabetle birlikte havayolları yolcu sayılarını artırmak için yeni uygulamaları faaliyete geçirerek müşteri memnuniyetini arttırma çabası içerisine girmişlerdir. Günümüzde internet, sosyal medya ve teknoloji unsuru aplikasyonlar dahil olmak üzere çeşitli makineleri kullanarak artan bu çeşitlilik ile birlikte havayolları yoğun bir müşteri kapma savaşı içerisindedirler. Özellikle Düşük Maliyet Stratejisi ile havayollarının harcamaları \%40-50 arasında düşmüş olup (Doganis, 2001), bu durum bilet fiyatlarına yaklaşık \%60 oranında yansımıs ve daha çok müşteri Sivil Havacılık Sektörüne çekilerek farklı uygulamalar ortaya çıkmışır. Bu çalışmada, havayollarının müşterilerin seçiminde ön plana çıkmak için uyguladıkları yöntemler ile beraber müşterilerin şikâyetleri ve Sivil Havacılık Sektöründe yolcuların beklentilerine yönelik çözümlemeler yer alacaktır.

\section{LITERATÜR INCELEMESI}

\subsection{Yolcu Memnuniyeti}

Günümüzde Havayolları için zamanında kalkış yapmak büyük önem arz etmektedir. Hatta bazı Havayolları zamanında kalkış ile ilgili personellerine bonus uygulamasını başlatmış ve bu şekilde zamanında kalkış konusunun çalışan personel tarafından daha çok önemsenmesini sağlamıştır. (Forbes et al., 2011, p. 771). Fakat günümüzde yolcuların Düşük Maliyetli Taşımacılık yapan Havayollarını konfor standartlarının çok düşmesinden dolayı sıklıkla eleştirdikleri gözlemlenmektedir. (Forbes, 2008, p. 193). Düşen konfor standartlarından dolayı müşteriler fiyatları da inceleyerek farklı Havayollarını denemektedir. Bu nedenle de belirli bir Havayoluna aidiyet duygusu oluşamamaktadır (Suzuki, 2000, p. 143). Yolcuların şikâyetçi oldukları başka bir konu da bilet fiyatlarının düşük olmasının dışında konfor standartlarının çok düşük ve ikramın olmaması durumlarına bir seviye konması gerektiğidir. (Prince ve Simon, 2015, p. 376). Ancak burada yolcuların düşünmedikleri bir konu bulunmaktadır. Zamanında kalkış konusunu yolcular az personel çalışıyor, bilet fiyatları düşük olduğundan konfor standartları çok düşmüş durumda gerçeğini hizmetin kalitesiz olmasına bağlamaktadırlar. Fakat Havayolları açısından bakıldığında, ne kadar ucuza bilet satılsa, ne kadar konfor ve hizmet standartları minimum seviyede tutulsa da zamanında kalkış olmadığı zaman Havaalanına ödenen ceza ve vergileri yolcular düşünmemektedir. Dolayısıyla zamanında kalkış performansı her ne kadar Düşük Maliyetli Havayollarının Sivil Havacılık Sektörüne \%40-50 harcamalar ile \%60 oranlarında bilet fiyatlarının düşmesi ve aynı güzergahta (destinasyon) yapılan seferleri 3-4 kat arttırsa da Havayolunun düşük maliyetli olmasına veya biletlerin ucuz olmasına bağlanamaz. (Roberts Roach and Associates, 2004). Fakat hava trafiği yoğunluğu artsa da zamanında kalkış Havaalanı Kapasitesi ile ilgili olmaktadır. Fakat Düşük Maliyetli Havayollarının yolcu ulaşımını maksimize eden stratejileri de Havaalanlarının kullanım oranlarını arttırmakta olup bu durumun Zamanında Kalkış Oranlarındaki gecikmelere yol açtığı ifadesi doğrudur. Bu konuda yapılması gereken Havayollarının stratejilerinin yanlışı̆̆ı değil, Dünya Sivil Havacılık Sektöründe artan yolcu sayısı ile birlikte Havaalanlarının gerek master (büyüme) planları gerekse yeni Havalimanlarının yapılması ile birlikte yolcu kapasitelerinin artmasının gerektiğidir. (Taneja, 2004)

\subsection{Havayolu Şirketlerinin Temel Sorunu: Zamanında Kalkış}

Günümüzde Sivil Havacılık Sektörünün hızlı büyümesi sonucunda havayollarının en büyük sorunu Havaalanı Kapasitelerinin yetersiz kalmasıdır. O nedenle de zamanında kalkış oranları Havaalanı Kapasitelerinin doygunluğa ulaşmasından dolayı da azalmaktadır. Avrupa Birliği Horizon 2020 Araştırma Programına göre Havaalanlarındaki tıkanıklığı minimuma indirmeyi sağlayacak bir sistem üzerine çalışmalar da bu sorunu çözmek amaçlıdır.(Raffarin, 2004 \& Santos ve Robin, 2010, p. 395). 2000 yılında Ocak, Nisan ve Temmuz aylarında 50 Havaalanı incelenerek yapılan bir araştırmaya göre, meteorolojik koşulların ve tarifelerin arka arkaya herşey yolunda olacakmış gibi çok sıkışık olması da kapasite aşımını tetiklemektedir. Mazzeo (2003). 2014 yııında yapılan araştırmada ise 100 ayrı Havaalanı geliş ve gidişlere göre analiz edilmiştir ve rekabetteki artışın gecikmelerdeki artışa yol açtığı net bir şekilde ortaya çıkmışır (Greenfield, 2014, p. 85). 2015 yılında yapılan ayrı bir araştırmaya göre de zamanında kalkış oranlarındaki düşüşler Amerika da Düşük Maliyetli Taşımacılık yapan Havayolları arasında en çok SouthWest Airlines'ı etkilemiştir. Bu etkileşim de SouthWest'in hizmet kalitesini düşürmüştür. (Prince ve Simon, 2015, p. 378). Düşük Maliyetli Havayolları arasındaki rekabet sadece bilet fiyatlarını azaltmadığı gibi düşük konfor standardı stratejisi benimsense dahi bu rekabet hizmet ve konfor standartlarındaki artışı da beraberinde getirmektedir. (Rupp ve Sayanak, 2008, p. 6). Uçuşlardaki gecikmelerin 2 temel sebebi bulunmaktadır. Bunlardan ilki hub (ana merkez) ve spoke (bağlantı noktaları) arasındaki bağlantılardaki stratejiler, ikincisi ise hava trafiğinden kaynaklanan tıkanıklıktır. Dar ile geniş gövdeli uçaklar arasında kuyruk türbülansını önlemek için en az 4 mil mesafe bırakmak gerekir. Bunu azaltmak risktir. Bu risk durumu da uzun vadede Havaalanlarındaki yoğunluğu arttııı ve dolayısıyla havada uçaklar boşa beklerler ve zamanında kalkış oranları da buna bağı olarak düşebilir. (Mayer ve Sinai, 2003, p. 1202). Uçuşlarda kalkış yapılan meydanla birlikte iniş yapılan meydanlardaki gecikmeler de zamanında kalkış oranını düşüren etkenlerden bir tanesidir. Kalkış yapılan meydanlardaki yoğunluk da rötara (gecikmeye) etkendir. Aynı şekilde iniş yapılan meydandan da kalkış yapılacağından bu zincirleme bir etki yaratmaktadır. Havalimanın pist sayısı da bunda etken olmaktadır. Özellikle yerde kalma süresi ve mevcut meydanın trafik yoğunluğu rötarların en büyük nedenlerinden biridir. Bu etkenlerin noktadan noktaya transferi en kısa sürede gerçekleştiren Düşük Maliyetli Havayollarını daha yoğun bir şekilde etkilemesinin sebebi de uçuşa hazırlanma için yerde kalma süresinin kısa olmasıdır. (Mayer ve Sinai, 2003, p. 1202). Menzili ve uçuş süresi kısa olan Düşük Maliyetli Havayollarının, yolcu kapasitesi fazla ve hava trafiği yoğun olan Havalimanlarıı kullanmaları da zamanında kalkış oranlarını arttırmaktadır. Çünkü bu uçakların kalkış ve iniş sayıları fazla olacağından rötarlar da buna bağlı olarak artacaktır. Ayrıca Düşük Maliyetli Havayollarının yerde kalma süresi (ground time)'ları da az olduğundan zamanında kalkıs oranları daha da düşmektedir (Rupp, 2009 , p. 27). Hub olarak kullanılan Havaalanları da hem kısa hem uzun menzilli uçuşların yoğunlukla yapıldığı Havaalanları olduğundan ve düşük maliyetli havayollarııı uçuş sürelerinin de 4-5 saate çıkması nedeniyle Havaalanı yoğunluğu arttırmakta ve bu durum rötarları tetiklemektedir. (Ater, 2012, p. 199).

\subsection{Havayolu Seçimini Belirleyen Unsurlar}

Havayollarının sayısının artması rekabet seviyesini arttırdığı gibi müşterilerin Havayolu seçimlerindeki beklentilerini de değiştirmektedir. (Ukpere et al., 2012, p. 5444). Birçok Havayolu müşteri potansiyeline uygun pazarlama stratejileri geliştirerek müşteri memnuniyetini arttırmaya çalışmaktadır. Sosyo-demografik ve yolculuk karakteristiklerindeki farklııklar da Havayolu seçimini etkilemektedir. (Gilbert ve 
Wong, 2003, p. 524). Müşterilerin tercih edecekleri Havayolu seçiminde 2 önemli faktör bulunmaktadır. Bunlar; hizmet kalitesi ve bilet fiyatlarıdır. (Alamdari, 1999, p. 205; Ukpere et al., 2012, 5445); Adeola ve Adebiyi, 2014, p. 68). Havayolu seçiminde birçok faktör bulunmaktadır fakat bu faktörler genellikle demografik özellikler ve seyahat karakteristiklerine göre biçimlenmektedir. (Gilbert ve Wong, 2003, p. 525). Yolcuların düşük maliyetli ve geleneksel (Legacy or Full Service Carrier) Havayolu seçimlerinde birçok belirleyici etken bulunmaktadır. Bu etkenler sosyo-demografik duruma ve yolculuk amacına göre değişiklik gösterir. (Mason ve Alamdari, 2007, p. 305 \& Chiou ve Chen, 2010, p. 227 \& Edwards, 2011). 1990'lı yıllarda hizmet kalitesi bilet fiyatlarına nazaran müşteri memnuniyetini daha çok etkileyen bir faktör olarak görülürken (Ostrowski et al., 1993, p. 18), 2000'li yıllarda bilet fiyatı hizmet kalitesine göre müşteri memnuniyetini daha çok etkileyen bir faktör olarak görülmektedir. (Hess vb., 2007, p. 225). Önceden alınan biletlerdeki fiyatların uygun olması ve bilet alındıkça verilen promosyonlar da müşteri memnuniyetini arttıran etkenleri oluşturmaktadır. (Dennett et al., 2000, p. 87). Ayrıca Havayolunun marka imajı da müşterilerin havayolunu seçiminde etken olmaktadır. (Connor ve Davidson, 1997). Bazı araştırmalarda gelir, yaş ve cinsiyet gibi sosyodemografik karakteristiklerde hizmet kalitesini farklılaştırmadır. Hizmet kalitesi gelir, yaş ve cinsiyete göre farklı şekillerde yorumlanmaktadır. (Clemes vb., 2008, p. 53). Yolculuk çeşitleri havayolu seçimini etkilemektedir. Gidilecek yer, yolculuğun amacı ve yolculuk süresi yolcuların Havayolu seçimlerinde etkili olmaktadır. (Castillo-Manzano ve Marchena-Gomez, 2011, p. 50). İş seyahatlerinin düşük maliyetli veya geleneksel taşımacılık ile yapılması, iş seyahatleri yapan yolcuların, tatil amaçlı seyahat yapan yolculara nazaran Havayolu seçimlerinin farklı olması sonucunu doğurmaktadır. İş amaçlı seyahat eden yolcular için hizmet kalitesi daha önemli olmaktadır. Rezervasyon yöntemleri, bilet ücretlerinin düzeyi ve yolcuların sezonluk uçuş programları için tarife endişeleri de Havayolu seçiminde önemli unsurları oluşturmaktadır. (Ong ve Tan, 2010, 211).

\subsection{Havayollarının Bilet Fiyatlarındaki Uygulamaları}

Havayollarının son yıllarda yaygın bir şekilde uyguladıkları sistem internet üzerinden bilet satışıdır. Bu sistemde gideceğin yer, gideceğin zaman ve bileti alış saatine göre bilet fiyatları değişmektedir. (Button ve Vega, 2007, p. 89). Bu sistemde bilet fiyatları sefer saati yaklaştıkça artmaktadır. Biletler seferden günler önce alındığı zaman ise oldukça ekonomik fiyatlarla bilet alınabilmektedir. Bu sistemde arz-talep dengesine göre müşteri potansiyeli hesaplanarak bilet fiyatları bu esaslar altında belirlenmektedir. (Rochet ve Tirole, 2003, p. 1003). Dinamik fiyatlandırma, kar maksimizasyonu arttırmak için uygulanan bir sistemdir. Bu sistemde anlık olarak internet ve yolcuların bilet fiyatlarına gösterdiği tepki hesaplanabilmektedir. Bu şekilde de müşteriyi mevcut havayoluna çekebilmek kolaylaşır. (Elmaghraby ve Keskinocak, 2003, p. 1293). Düşük Maliyetli Havayollarında bilet fiyatları esas alındığında tutarsızlık görünse de yolcuya düşen görev bu sisteme uyum sağlandığı zaman ucuz bilet alabileceğinin bilinmesi gerektiğidir. Başka bir deyişle, yolcular için tutarsızlık görünse de mevcut sisteme uyulduğu zaman bu durum avantaja çevrilebilir. (Graf, 2004).

\subsection{Havayollarının İnternet Üzerinden Bilet Satış Sistemi Nasıl Çalışır}

İnternet üzerinden bilet satış sistemi 2 şekilde çalışmaktadır. İlki; müşterilerin arz ve talepleri ile birlikte sefer saatine kalan zaman esas alınarak hesaplama yapılmasıdır (Ramón-Rodríguez, Moreno-Izquierdo ve Perles-Ribes, 2011, p. 112). Bu sistemde anlık olarak kalan koltuk sayısı ve güzergâhın müşteriler için popülaritesi önemli olmaktadır.(Dana ve Orlov, 2009). İkincisi; rakip havayollarının da simultane olarak bilet fiyatlandırmaları incelenerek, birçok güzergâh ve bilet fiyatı aynı anda gözlemlenerek anlık uygun fiyat stratejisi esas alınmaktadır. Bu şekilde de müşterileri mevcut havayoluna çekmek kolaylaşacaktır. (Ackerman, 2006). Yüksek orta ve düşük bütçeli harcamaların da değişken olması özellikle bilet satışlarında internetin yoğun kullanımı ile beraber karın maksimize edilmesi konusunda Düşük Maliyetli Havayollarına katkı sağlamaktadır. (Bilotkatch, 2005, p. 335 \& Aydin ve Morefield, 2010, p. 3). Sivil Havacılık Sektöründe son yıllarda ücretlerin düzenlenmesi konusu ile ilgili olarak fiyat dağılımı ve kar maksimizasyonu konusunda birçok yenilik yaşanmaktadır. (Anjos, Russell, Cheng ve Currie, 2005 \& Otero ve Akhavan-Tabatabaei, 2015). Ayrıca harcamalarda dikkate değer yer tutan yakıt fiyatlarındaki hedge (fiyat ayarlaması) imkânı ile yakıt ve yağ fiyatlarındaki düzenlemeler de kar maksimizasyonu destekler niteliktedir. (Dresner, Lin ve Windle, 1996, p. 317 \& Verlinda ve Lane, 2004). Fiyat dağılımı düşük maliyetli havayollarının ortaya çıkması ile birlikte daha aşırı hale gelmiştir. Bu durumdan dolayı düşük maliyetli havayolları personel maliyetleri, konfor ve hizmetle ilgili maliyetleri düşürerek kar maksimizasyonunu bu ortamda dahi olumlu seviyelere getirebilmişlerdir. (Schipper, Nijkamp ve Rietveld, 2007, p. 198). Özellikle düşük maliyetli havayolları Avrupa pazarında çok etkindir. Amerika'da genellikle büyük çapta olmayan havayolları düşük maliyetle taşımacılık yapmaktadır. (McAfee ve te Velde, 2006). Düşük maliyetli havayollarındaki fiyat dağılımı seferden uzun zaman önce bilet satışı başladığı zaman ve gün geçtikçe belli oranda artan bir fiyatlandırma sistemidir. Fakat tek belirleyici durum bu değildir. Ryanair ve EasyJet gibi Dünyanın önce gelen düşük maliyetli havayolları bu sistemi yolcuların fiyatlara anlık tepkilerini hesaplayacak bir şekilde geliştirmişlerdir. (Malighetti, Paleari ve Redondi, 2010, p. 38). Bu stratejide uçağın tarifeli kalkış saatine birkaç gün kala hizmet ve konfor standartlarının yüksek olduğu geleneksel havayollarına göre daha yüksek fiyata bilet satışı yapılmaktadır. Eğer düşük maliyetli havayollarından bileti birkaç hafta önceden alırsanız düşük fiyatlardan faydalanılabilmektedir. Buradaki hesaplama uçaktaki toplam kişi sayısının çok önceden belli olarak ona göre planlama yapılması ve mevcut uçuşu en kısa sürede doldurarak maddi kazancı uzun vadede daha yüksek meblağlara çıkartmaktır. (Piga ve Bachis, 2007). Fiyatın farklılaşması pazarın yoğunluğuna bağlı olarak değişen bir stratejidir. Halen tam olarak bu stratejinin havayolları tarafından nasıl yapıldığı ile ilgili net ve kesin bir bilgilendirme bulunmamaktadır. Fakat Düşük Maliyetli Havayolları bu stratejiyi en karlı şekilde yönetmektedirler. Ancak yönetilen bu strateji Düşük Maliyetli Havayolları arasında da değişkenlik göstermektedir. ( Borenstein, 1989 , p. 351 \& Hayes ve Ross, 1998, p. 527 \& Stavins, 2001 , p. 204).

\subsection{Havayollarının İnternet Üzerinden Hizmet Türleri}

Ayrıca Sivil Havacılık Sektöründe online hizmetlerin kullanımı yoğun oranda yaygınlaşmaktadır. Bu hizmetler online biletleme ve online check_in (kiosk) ve bunun gibi elektronik sistemleri oluşturur. Online hizmetleri iyi şekilde kullanmak hizmet kalitesini arttıracağı gibi, işletme maliyetlerini düşürecek ve bir yandan da müşterilere farklı seçim imkânları sunulmuş olunacaktır. (vb., 2009). Online hizmetlerle ilgili en çok kullanılan sistem kendi kendine check_in hizmetidir (self service check-in). Bu sistemde yolcu havalimanına geldiğinde el bagajı dışında bagajı yoksa check-in bölümüne uğramadan uçağa biniş (boarding) işlemlerini yapabilmektedir. Bunun dışında online sistemler içinde web ve mobil telefon uygulamaları da kullanılmaktadır. International Air Transport Association (IATA) da Hızı Seyahat (Fast Travel) programı ile bu gelişmeleri hızlandırmaktadır. (IATA, 2015a). Online hizmetler yolcuların işlemlerini kolaylaştırmaktadır. Bu nedenle de bu sistemler hem 
Havayolları için hem de yolcular için böylesine yoğun işleyen bir Sivil Havacılık Trafiği içinde büyük bir zaman kazancı olmuştur. (Curran ve Meuter, 2005, p. 106). Havayolları bu yenilikler üzerinde yoğun şekilde çalışmakta olup müşteriler de zaman kazancından ve işlemlerin kolaylaşmasından dolayı mutludur. Ancak kendi kendine check-in (kiosk makinası) ve bunun gibi diğer elektronik ekipmanların kullanımı konusunda yolcular tam olarak bilgi sahibi olamamışlardır. (Lu vb., 2009, p. 349). Bu yeni teknolojik aygıtların kullanılması için en önemli husus benimsenmelerinin sağlanmasıdır. En zor konu yolcuların bu makineleri kullanmayı benimsemeleridir. Yolcular bu makineleri kullanmaya alıştıkları zaman daha sonraları daha yoğun şekilde kullanmaya devam etmektedirler. (Wang vb., 2013, p. 410). Yeni buluşların müşteriler tarafından yaygın şekilde kullanılmasının sağlanması için 6 aşamanın yerine getirilmesi gerekmektedir. Bu aşamalar; farkında olma, araştırma, değerlendirme, deneme, tekrarlanan kullanım ve taahhüt olmaktadır. (Rogers, 1995). Eğer müşteriler yeni bir sistemi ilk denediklerinde sistemin rahatlığı ve kolaylığı açısından ilk algı iyi olduğunda, daha sonraki zamanlarda bu sistemi kullanmaya devam etmektedirler. Önemli olan ilk tecrübenin iyi, doğru ve olumlu şekilde edinilmesidir. Daha sonra iyi edinilen bu tecrübenin devamı gelmektedir. (Karahanna vb., 1999, p. 191; Lee vb., 2011).

\section{YÖNTEM}

\subsection{Atlı Kıstas Altında Avrupa Pazarındaki Sistem Anlayışı}

Avrupa ülkelerinde altı temel strateji esas alınarak bilet fiyatlarındaki uçurum yolcuyu çok erken zamanlarda bilet almaya, eğer yolcuların bu imkanı yoksa da farklı ulaşım imkanları aramaya veya bu gibi durumlarda tatil yapmamaya ve geleneksel taşımacılığa yönelmeye kadar etkilemiştir. (Giaume ve Guillou, 2004, p. 306 \& Gerardi ve Shapiro, 2007 \& Gaggero ve Piga, 2011, p. 557). Bu stratejilerin uygulandığı Avrupa Ülkelerinde yolcuların havayolu tercihini yoğunlukla değiştirmesi, geleneksel ve charter sistemini uygulayan havayollarının da fiyatlandırmalarını düşük maliyetli taşımacılık esasına göre yapmalarıdır. Avrupa da Geleneksel ve Charter Taşımacılık Stratejisini uygulayan Havayolları da bilet fiyatlarını yolculuk süresi yaklaştıkça belirli oranda artan bir sistem dâhilinde planlamaktadırlar. (Giaume ve Guillou 2004). Farklı şekilde ifade edildiğinde, Avrupa pazarındaki rekabet anlayışında Geleneksel, Charter ve Düşük Maliyetli Havayolları aynı stratejiyi farklı fiyat ayarlamaları eşliğinde kullanmaktadır. Bu nedenle de bilet fiyatları Avrupa pazarı dışına göre büyük oranda farklılaşmaktadır. (Alderighi, Cento, Nijkamp ve Rietveld, 2011, p. 228). Ryanair ve EasyJet gibi düşük maliyetli taşımacılığın önde gelen havayolları bilet fiyatlandırmasını diğer Düşük Maliyetli Havayollarına göre farklı şekilde yapmaktadır. Diğer Düşük Maliyetli Havayolları haftaiçi, haftasonu ve sefer saati uygulamalarını öncelikli olarak düşünürken (Malighetti, vb., 2010); Ryanair ve EasyJet bu uygulamayı daha da geliştirerek uçuşun hangi güzergaha yapıldığını hatta havalimanı seçimi de dahil olmak üzere çok yönlü bir şekilde tüm detayları hesaba katmaktadır. (Salanti, Malighetti \& Redondi, 2012, p. 253), Bu şekilde dönemsel güzergâhların arz-talep dengesi daha net bir şekilde anlaşılarak buna uygun fiyatlandırma stratejisi ile rakiplerinden daha etkin şekilde faaliyetlerini sürdürmektedirler. Bu stratejinin doğru olarak uygulanmasının zorluğu da aşikârdır. Bu sistem tam ve kesin olarak doğru şekilde uygulanamazsa mevcut havayolunun karlığını azaltabileceği gibi zarar da ettirebilir. (Salanti, vb., 2012, p. 253).

\section{SONUÇ VE ÖNERILER}

Sivil Havacılık Sektörü tüm dünyada büyüme ivmesi içerisindedir. Bu ivmenin yeni yapılan ve yapılacak Havaalanları ile Havayollarının uçak ve personel alımlarının artması unsurları göz önüne alındığında daha da büyüyeceği açık şekilde görülmektedir. Sivil Havacılık Sektörü 24 saat çalışmanın olduğu vardiya sistemine bağıı bir yapı olduğundan dolayı da yüksek sayıda personeli bünyesinde bulundurmaktadır. Büyüyen Sivil Havacılık Sektöründe dolayısıyla rekabet de artmaktadır. Havayolları müşterileri çekebilmek için farklı stratejiler düşünmekte ve bunları en iyi şekilde uygulamak zorundadırlar. Aksi halde böylesine rekabetin büyük olduğu bir pazarda ayakta kalabilmek daha da zorlaşacaktır. Müşteriyi çekebilmenin yolu ise bilet fiyatı, konfor ve hizmeti standartlarını en optimum seviyede tutabilmektir. Geleneksel, Charter ve Düşük Maliyetli Taşımacılık gibi birçok stratejinin uygulandığı Sivil Havacılık Sektöründe her bir strateji için optimum fiyat-konfor-hizmet dengesi önemli olmaktadır. Günümüzde Düşük Maliyetli Havayollarının çok rağbet görmesi, müşterilerin Havayolu seçiminde en çok fiyat unsurunu önemsediklerini göstermektedir. Her ne kadar konfor ve hizmet kavramları beraber değerlendirildiğinde, genellikle işadamları tarafından konfor ve hizmet faktörünün fiyata nazaran daha önemli olduğu görülse de Düşük Maliyetli Taşımacılık anlayışı sektöre farklı bir boyut kazandırmıştır. (US Department of Transportation, 1996, p.13). Ancak 11 Eylül 2001 Krizinden sonra Sivil Havacılık Sektöründe yaşanan önlenemez düşüşü düzelten ve sektörü müşteriler tarafından daha cazip kılan, uçağa binmeyi lüks olmaktan çıkartan Düşük Maliyetli Taşımacılık Stratejisi ile uygulanan düşük fiyat konsepti müşterilerin en çok tercih ettiği model olup, Havayolu seçimindeki en önemli unsuru fiyat olarak açıkça ortaya koymaktadır. Günümüzde Geleneksel ve Charter Taşımacılığı benimseyen Havayolları da Düşük Maliyetli Havayollarının uyguladığı stratejileri benzer bir fiyat-konfor-hizmet dengesi ile Düşük Maliyetli Havayolları ile pazar paylarını daha fazla kaptırmamak için rekabete girmiş durumdadırlar.

\section{KAYNAKÇA}

Ackermann, J. A., (2006). Price discrimination and the internet, PhD Dissertation, Duke University.

Alamdari, F. (1999). Airline in-flight entertainment: the passengers' perspective. J. Air Transp. Manag. 5 (4), p. $203-209$

Ater, I. (2012). Internalization of congestion at U.S. hub airports. J. Urban Econ. 72 (2), p. 196-209.

Adeola, M. M., Adebiyi, S. O. (2014). Service quality, perceived value and customer satisfaction as determinant of airline choice in Nigeria. Int. Lett. Soc. Humanist. Sci. 20 (2014), p. 66-80.

Alderighi, M., Cento, A., Nijkamp, P., Rietveld, P. (2012). Competition in the European aviation market: the entry of low-cost airlines Journal of Transport Geography, 24, p. 223-233. 
Aydin, R., Morefield, R. (2010). Hub-And-spoke airlines vs low-cost airlines and price discrimination Journal of Business \& Economics Research, $8(5)$, p. 1-6.

Bilotkatch, V. (2005). Understanding price dispersion in the airline industry: capacity constraints and consumer heterogeneity, in: L. Darin (Ed.), Advances in Airline Economics, 1Elsevier), p. 329-345.

Borenstein, S. (1989). Hubs and high fares: dominance and market power in the U.S. airline industry RAND Journal of Economics, 20 (3), p. 344-365.

Button, K., Vega, H. (2007). The uses of the 'temporal-fare-offered curve' in air transportation. Transportation Research Forum, 46 (2), p. 8399.

Castillo-Manzano, J. I., Marchena-Gomez, M. (2011). Analysis of the determinants of airline choice: the LCC passenger. Appl. Econ. Lett. 18, p. 49-53.

Chiou, Y. C., Chen, Y. H. (2010). Factors influencing the intentions of passengers regarding full service and low-cost carriers: a note. J. Air Transp. Manag. 16 (4), p. 226-228.

Clemes, M. D., Gan, C., Kao, T. H., Choong, M. (2008). An empirical analysis of customer satisfaction in international air travel. Innov. Mark. 4 (2), p. 50-62.

Connor, D., Davidson, J. (1997). Marketing Your Consulting and Professional Services. Wiley, New York.

Curran, J. M., Meuter, M. L. (2005). Self-service technology adoption: comparing three technologies. J. Serv. Mark. 19 (2), p. $103-113$.

Dana, J. D., Orlov, E. (2009). Internet penetration and capacity in the US airline industry, Northeastern university college of business administration, Research Paper 08-001.

Dennett, C., Ineson, E. M., Stone, G. J., Colgate, M. (2000). Pre-bookable services in the chartered airline industry: increasing satisfaction through differentiation. Serv. Ind. J. 20, p. 82-94.

Doganis, R. (2001). The Airline Business in the 21st Century Routledge, London.

Dresner, M., Lin, J. S., Windle, R. (1996). The impact of low-cost carriers on airport and route competition Journal of Transport Economics and Policy, 30 (3), p. 309-328

Edwards, J. E. (2011). Key Characteristics and Attitudes of Airline Passengers, with Particular Emphasis upon the Low-cost Sector: Implications for Free-trip Decision-making and Airline Choice. Phd research of the University of Westminster, October 2011.

Elmaghraby, W., Keskinocak, P. (2003). Dynamic pricing in the presence of inventory considerations: research overview, current practices, and future directions Management Science, 49 (10), p. 1287-1309.

Forbes, S., (2008). The effect of service quality and expectations on customer complaints. J. Ind. Econ. 56 (1), p. $190-213$.

Forbes, S., Lederman, M. (2010). Does vertical integration affect firm performance? Evidence from the Airline Industry. RAND J. Econ. 41 (4), p. 765-790.

Gaggero, A. A., Piga, C. A. (2011). Airline market power and intertemporal price dispersión The Journal of Industrial Economics, 59 (4), p. 552577.

Giaume, S., Guillou, S. (2004). Price Discrimination and concentration in European airline markets Journal of Air Transport Management, 10 (5), p. 305-310.

Gerardi, K., Shapiro, A. H. (2007). Does competition reduce price discrimination? New evidence from the airline industry Federal Reserve Bank of Boston Publications.

Gilbert, D., Wong, R. K. C. (2003). Passengers expectations and airline services: a Hong-Kong based study. Tour. Manag. 24, p. $519-532$.

Graf, L. (2004). Incompatibilities of airline business models in the same entrepreneurial system. Paper to the ATRS World Conference, Istanbul.

Greenfield, D. (2014). Competition and service quality: New evidence from the airline industry Econ. Transp., 3, p. 80-89.

Hayes, K., Ross, L. B. (1998). Is airline price dispersion the result of careful planning or competitive forces? Review of Industrial Organization, 13, p. $523-541$

Hess, S., Adler, T., Polak, J. W. (2007). Modeling airport and airline choice behavior with the use of stated preference survey data. Transp. Res. Part E Logist. Transp. Rev. 43 (3), p. 221-233.

IATA, (2015a). Fast Travel Program. <www.iata.org> (Erişim Tarihi 12.03.19).

Lu, J., Chou, H. Y., Ling, P. C. (2009). Investigating passengers' intentions to use technology-based self check-in services. Transp. Res. Part E: Logist. Transp. Rev. 45 (2), p. 345-356.

Karahanna, E., Straub, D. W., Chervany, N. L. (1999). Information technology adoption across time: a cross-sectional comparison of preadoption and postadoption beliefs. MIS Q. 23 (2), p. 183-213. 
Malighetti P., Paleari S., Redondi R. (2010). Has Ryanair's pricing changed over time? An empirical analysis of its 2006-2007 flights Tourism Management. 31, p. 36-44.

Mason, K. J., Alamdari, F. (2007). EU network carriers, low cost carriers and consumer behavior: a Delphi study of future trends. J. Air Transp. Manag. 13, p. 299-310.

Mayer, C., Sinai, T. (2003). Network effects, congestion externalities, and air traffic delays: or why all delays are not evil. Am. Econ. Rev. 93 (4), p. 1194-1215.

McAfee R., te Velde L. (2006). Dynamic pricing in the airline industry T.J. Hendershott (Ed.), en: Handbook on Economics and Information Systems (1, ed), Elsevier Science, New York.

Ong, W. L., Tan, A. K. G. (2010). A note on the determinants of airline choice: the case of Air Asia and Malaysia Airlines. J. Air Transp. Manag. 16 (4), p. 209-212.

Ostrowski, R. L., O’ Brien, T. V., Goedon, G. L. (1993). Service quality and customer loyalty in the commercial airline industry. J. Travel Res. 32 , p. 16-24.

Roberts Roach and Associates. (2004). What is price elasticity. http://r2ain.com/pdfs/pr_elas.pdf, 7.

Rupp, N. (2009). Do carriers internalize congestion costs? Empirical evidence on the internalization question. J. Urban Econ. 65 (1), p. $24-37$.

Rupp, N., Sayanak, T. (2008). Do low cost carriers provide low quality service? Rev.Anal. Econ. 23 (1), p. 3-20.

Rochet J. C., Tirole J. (2003). Platform competition in two-sided markets Journal of the European Economic Association, 1 (4), p. $990-1029$.

Piga, C. A., Bachis, E. (2006). Pricing strategies by European traditional and low cost airlines: or, when is it the best time to book on line?. When is it the Best Time to Book on Line.

Prince J., Simon D. (2015). Do incumbents improve service quality entry? Evidence from airlines' on-time performance Manag. Sci., 61 (2), p. $372-390$.

Ramón-Rodríguez A. B., Moreno-Izquierdo L., Perles-Ribes J. F. (2011). Growth and internationalisation strategies in the airline industry Journal of Air Transport Management, 17, p. 110-115.

Salanti A., Malighetti P., Redondi R. (2012). Low-cost pricing strategies in leisure markets Tourism Management, 33, p. $249-256$.

Santos, G., Robin, M. (2010). Determinants of delays at European airports Transp. Res. Part B: Methodol., 44 (3), p. $392-403$.

Schipper, Y., Nijkamp, P., Rietveld, P. (2007). Deregulation and welfare in airline markets: an analysis of frequency equilibria European Journal of Operational Research, 178 (1), p. 194-206.

Stavins, J. (2011). Price discrimination in the airline market: the effect of market concentration The review of Economics and Statistics, 83 (1), p. 200-212.

Suzuki, Y. (2000). The relationship between on-time performance and airline market share: a new approach. Transp. Res. Part E: Logist. Transp. Rev. 36 (2), p. 139-154.

Taneja, N. K. (2004). Simpli-Flying: Optimizing the Airline Business Model Ashgate, Aldershot.

Ukpere, W. I., Stephens, M. S., Ikeogu, C. C., Ibe, C. C., Akpan, E. O. P. (2012). Determinants of airline choice-making: the Nigerian perspective. Afr. J. Bus. Manag. 6 (15), p. 5442-5455.

US Department of Transportation. (1996). The Low Cost Service Revolution. US Department of Transportation, Office of Aviation and International Economics, April, p. 11-17.

Verlinda, J. A., Lane, L. (2004). The Effect of the Internet on Pricing in the Airline Industry, mimeo, URL http://ssrn.com/abstract=965788

Wang, C., Harris, J., Patterson, P. (2013). The roles of habit, self-efficacy, and satisfaction in driving continued use of self-service technologies: a longitudinal study. J. Serv. Res. 11 (4), p. 407-428. 